\title{
Micropore Structures in Cenosphere-Containing Cementitious Materials Using Micro-CT
}

\author{
Seyoon Yoon and Inhwan Park \\ Department of Civil Engineering, Kyonggi University, 154-42 Gwanggyosan-ro, Yeongtong-gu, Suwon 16227, Republic of Korea \\ Correspondence should be addressed to Seyoon Yoon; yoonseyoon@gmail.com
}

Received 21 March 2017; Accepted 3 May 2017; Published 11 June 2017

Academic Editor: Xiao-Yong Wang

Copyright (C) 2017 Seyoon Yoon and Inhwan Park. This is an open access article distributed under the Creative Commons Attribution License, which permits unrestricted use, distribution, and reproduction in any medium, provided the original work is properly cited.

\begin{abstract}
Cenospheres have been recently applied to increase the volume of uniform micropores in hardened cementitious materials. Therefore, application of micro-CT to cenosphere-containing binders will help better understand the micropores formed by cenospheres in the hardened materials. Accordingly, the present study prepared Portland cement paste, alkali-activated fly ash/silica fume, and alkali-activated fly ash with $60 \%$ weight replacement by cenospheres and reconstructed their micropore structures using micro-CT. From the pore structure, individual micropores were extracted and analyzed using the principal moment ratios $\left(I_{11} / I_{33}\right.$ and $\left.I_{22} / I_{33}\right)$. Based on the moment ratios, the representative pore shapes were determined in the different pore-volume ranges. Four-factor pore compliance contribution (4-factor PCC) model was then applied to predict the influences of the micropores on the elastic moduli of the micropore/matrix composites.
\end{abstract}

\section{Introduction}

Fly ash, a waste material produced by coal-fired power plants, has been applied to cement and concrete technologies to replace Portland cement [1-3]. Fly ash particles have three main morphologies: solid sphere, cenosphere, and plerosphere $[4,5]$. Among these, cenospheres can be separated due to having the lowest specific gravity; because of the hollow structure, they are substantially less dense than solid spheres and plerospheres. Therefore, cenospheres have been applied to fabricating lightweight concrete [69]. Furthermore, the presence of cenospheres in concrete structures can produce more uniform micropores, allowing these structures to achieve greater energy efficiency with a minimum reduction in strength $[9,10]$. This is because cenospheres increase the volume of uniform micropores in the hardened materials.

As cenosphere particles range in size from 10 to $400 \mu \mathrm{m}$ [11], they contribute to the formation of micropores. However, because of cenospheres' low reactivity, their micropore structures will differ depending on the cementitious material, such as geopolymers and Portland cement. Therefore, it is required to study more detailed pore shapes and the influences of micropores on the mechanical properties of cenosphere-containing cementitious pastes. Recent research on the application of micro-CT to cement and concrete has shed light on the detailed pore structures of cementitious materials [12-15]. In addition, an analysis method developed by Drach et al. [16], called the four-factor pore compliance contribution (4-factor PCC) model, allows us to predict the influence of individual pores on elastic moduli using the Mori-Tanaka method and statistical methods. Therefore, now is an ideal time to look at the detailed pore structures formed by cenospheres and their influence on elastic moduli, using micro-CT technology.

In the present study, we first constructed 3D micropore structures in cenosphere-containing cementitious matrixes using micro-CT. For this, three samples were prepared: alkali-activated fly ash-silica fume, alkali-activated fly ash, and Portland cement paste with cenospheres comprising $60 \%$ of binders by weight. We used a $\mathrm{Ca}(\mathrm{OH})_{2}-\mathrm{Na}_{2} \mathrm{CO}_{3}$ activator because a recent study showed that this activator is less expensive and less dangerous than $\mathrm{NaOH}$ without compromising the compressive strength [17]. Furthermore, 
TABLE 1: Mixture proportions of the samples: w/s denotes water-to-solid ratio (in grams).

\begin{tabular}{lcccccccc}
\hline Sample label & Portland cement & Fly ash & Silica fume & Cenosphere & $\mathrm{Ca}(\mathrm{OH})_{2}$ & $\mathrm{Na}_{2} \mathrm{CO}_{3}$ & Sucrose & Water \\
\hline FASF & - & 20 & 20 & 60 & 30 & 8 & 0.69 & 48.3 \\
& - & 40 & - & 60 & 30 & 8 & 0.69 & $48.35)$ \\
FA & 40 & - & - & 60 & - & - & - & $(\mathrm{w} / \mathrm{s}=0.35)$ \\
PC & & & & & & & 35 \\
\hline
\end{tabular}

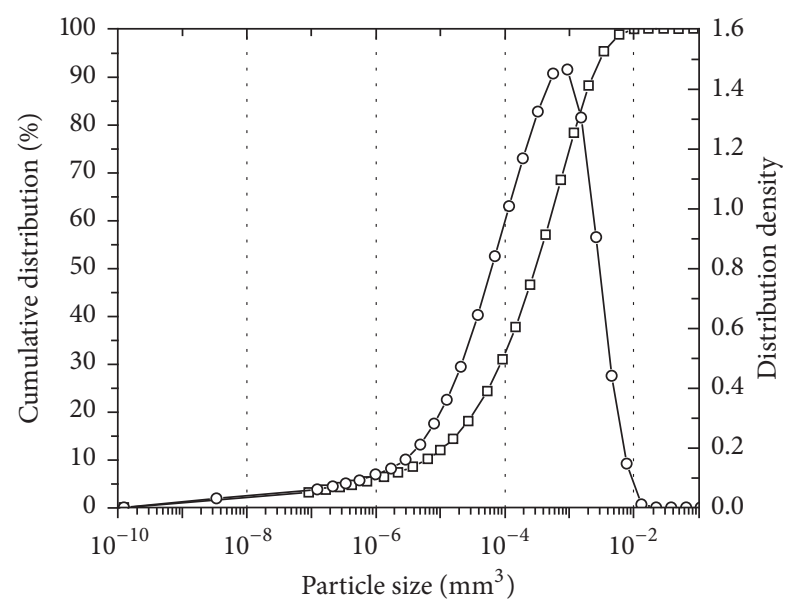

FIGURE 1: Particle size distribution of cenospheres (QK150).

the sample with silica fume was included because McBride et al. reported that the addition of silica fume improves the compressive strength of cenosphere-containing concrete [7]. The 3D micropores obtained from micro-CT were grouped on the basis of individual pore volumes $\left(<10^{-4} \mathrm{~mm}^{3}\right.$, $10^{-4} \sim 10^{-3} \mathrm{~mm}^{3}, 10^{-3} \sim 10^{-2} \mathrm{~mm}^{3}$, and $\left.\geq 10^{-2} \mathrm{~mm}^{3}\right)$. Based on these groups, each micropore was individually extracted; then the principal moments of inertia $\left(I_{11}, I_{22}\right.$, and $\left.I_{33}\right)$ were calculated to obtain the contour maps of $I_{11} / I_{33}$ and $I_{22} / I_{33}$ ratios. These ratios also provided numeric values to identify which representative pore shapes were most frequently observed. Lastly, we applied the 4-factor PCC model to predict the influence of the micropores on the elastic moduli of the cementitious composites.

\section{Experimental Details}

The present study used ASTM Type I Portland cement known as ordinary Portland cement (OPC) and silica fume marketed by Elkem AS under the product name ElkemMicrosilica ${ }^{\circledR}$ 940U. The cenospheres (product name QK150) and the fly ash, which is the original fly ash of cenospheres, were obtained from Spheretek Ltd. (Hong Kong). Wang et al. reported that cenospheres have substantial amount of amorphous phase and crystalline phases, such as mullite and quartz [8]. The particle size distribution of the cenospheres is presented in Figure 1, showing a range of $10^{-10}$ to $10^{-1} \mathrm{~mm}^{3}$.

We prepared three samples: alkali-activated fly ash-silica fume, alkali-activated fly ash, and Portland cement paste. All three samples contained cenospheres at $60 \%$ binders by weight. Cenospheres are considered as a binder component, because they contribute to long-term strength. The fly ashsilica fume and fly ash samples were activated using $\mathrm{Ca}(\mathrm{OH})_{2}$ (Junse Chemical, Japan) and $\mathrm{Na}_{2} \mathrm{CO}_{3}$ (Sigma Aldrich, USA). The water-to-solid ratio was maintained at 0.35 for all samples because it was the lowest mixable ratio. The detailed mixture proportion and sample labels are provided in Table 1. The samples were prepared with cylinder molds of $100 \mathrm{~mm}$ in diameter and then cured at room temperature $\left(20 \sim 22^{\circ} \mathrm{C}\right)$ in $99 \%$ relative humidity for 28 days. Micro-CT scans were performed with a SkyScan 1173 CT scanner at $130 \mathrm{kV}$ and $60 \mu \mathrm{A}$. The $2 \mathrm{D}$ image data had an image resolution of $18.11 \mu \mathrm{m} /$ pixel. Exposure time per projection was $500 \mathrm{~ms}$ with a $0.2^{\circ}$ step angle.

\section{4-Factor PCC Model}

Drach et al. developed the 4-factor PCC model to evaluate the influence of micropores on elastic moduli including Young's modulus $(E)$, bulk modulus $(K)$, and shear modulus $(G)$ $[16,18] .4$-factor PCC is a statistical model to give a prediction from input variables obtained from variation in irregular pore geometries. Finite-element analysis was performed on the basis of a large set of irregular pores. This process constructs a statistical formula to relate pore geometry parameters and their contribution to effective elastic properties. The 4 -factor PCC model is the statistical formula as follows:

$$
\begin{aligned}
\widetilde{E}_{i}, \widetilde{K} \text { or } \widetilde{G}= & \alpha_{0}+\alpha_{1} \widetilde{I}_{11}+\alpha_{2} \widetilde{I}_{22}+\alpha_{3} \widetilde{S}_{V}+\alpha_{4} \widetilde{v}+\alpha_{5} \widetilde{I}_{11}^{2} \\
& +\alpha_{6} \widetilde{I}_{11} \widetilde{I}_{22}+\alpha_{7} \widetilde{I}_{22}^{2}+\alpha_{8} \widetilde{I}_{11} \widetilde{S}_{V}+\alpha_{9} \widetilde{I}_{22} \widetilde{S}_{V} \\
& +\alpha_{10} \widetilde{S}_{V}^{2}+\alpha_{11} \widetilde{I}_{11} \widetilde{v}+\alpha_{12} \widetilde{I}_{22} \widetilde{v}+\alpha_{13} \widetilde{S}_{V} \widetilde{v} \\
& +\alpha_{14} \widetilde{v}^{2}
\end{aligned}
$$

where $\alpha_{i}$ and $\alpha_{i j}$ s are model coefficients, and the other values represent the following terms:

$$
\begin{aligned}
\widetilde{I}_{11} & =\frac{I_{11} / I_{33}-\operatorname{AVG}\left(I_{11} / I_{33}\right)}{\operatorname{MID}\left(I_{11} / I_{33}\right)}, \\
\widetilde{I}_{22} & =\frac{I_{22} / I_{33}-\operatorname{AVG}\left(I_{22} / I_{33}\right)}{\operatorname{MID}\left(I_{22} / I_{33}\right)}, \\
\widetilde{S}_{V} & =\frac{S_{V}-\operatorname{AVG}\left(S_{V}\right)}{\operatorname{MID}\left(S_{V}\right)}, \\
\widetilde{v} & =\frac{v-\operatorname{AVG}(v)}{\operatorname{MID}(v)},
\end{aligned}
$$




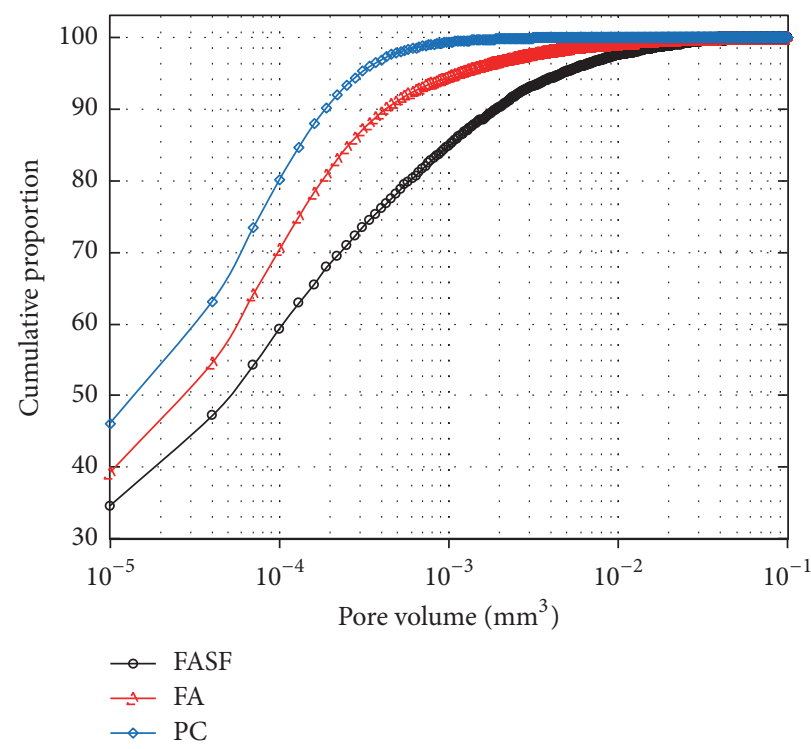

FIGURE 2: Pore-volume distributions of FASF, FA, and PC samples obtained from micro-CT data.

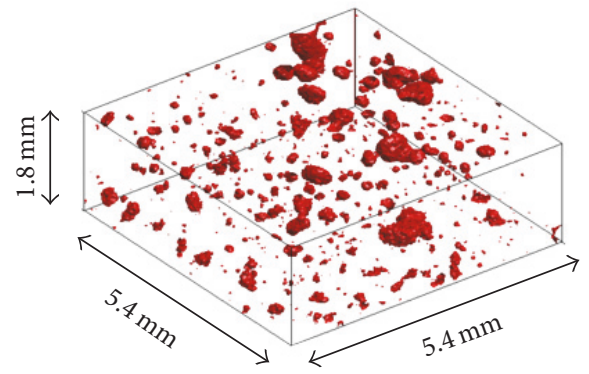

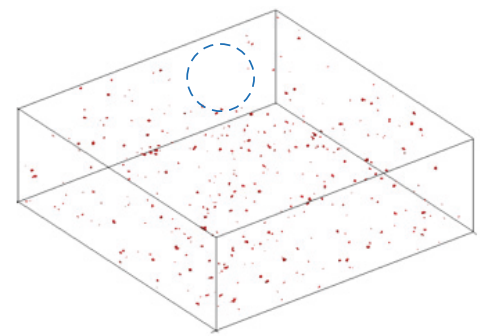

Pore volume: $<10^{-4} \mathrm{~mm}^{3}$

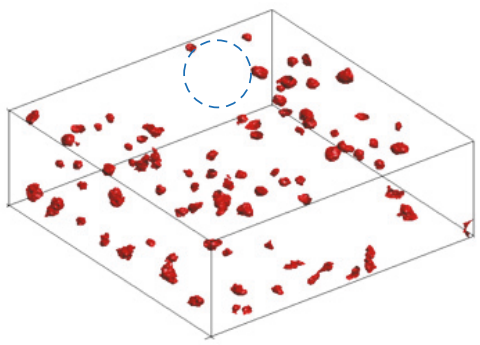

Pore volume: $10^{-3} \sim 10^{-2} \mathrm{~mm}^{3}$

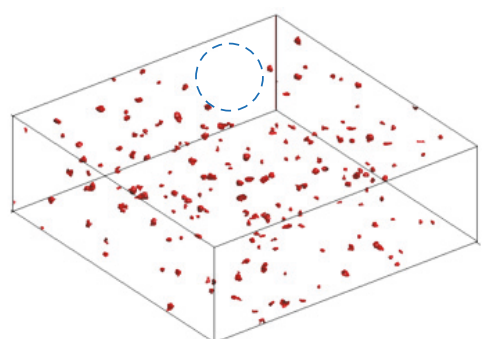

Pore volume: $10^{-4} \sim 10^{-3} \mathrm{~mm}^{3}$

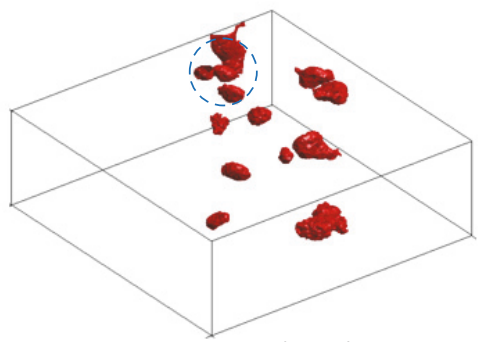

Pore volume: $\geq 10^{-2} \mathrm{~mm}^{3}$

FIGURE 3: Reconstructed 3D micropore structures of the FASF sample (separated micropores based on pore-volume ranges).

where MID is a midrange value, $S_{V}$ is surface area-to-volume ratio, and $v$ is Poisson's ratio. The dimensionless parameters $\left(\widetilde{E_{i}}, \widetilde{K}, \widetilde{G}\right)$ of the 4 -factor PCC model are the influential degree of micropores as follows:

$$
\begin{aligned}
\frac{E_{i}}{E_{0}} & =\frac{1}{1+p \widetilde{E_{i}}}, \\
\frac{K}{K_{0}} & =\frac{1}{1+p \widetilde{K}}, \\
\frac{G}{G_{0}} & =\frac{1}{1+p \widetilde{G}},
\end{aligned}
$$

where $p$ is a volume fraction of pores and $E_{0}, K_{0}$, and $G_{0}$ are the elastic moduli of the matrix. For a detailed discussion of the 4-factor PCC model, see [16].

\section{Results and Discussion}

4.1. Micropore Distribution. Figure 2 shows the cumulative proportion of the micropore volumes in the range of $10^{-5}$ to $10^{-1} \mathrm{~mm}^{3}$. The FASF, FA, and PC samples have different micropore distributions; the PC sample had an $80 \%$ volume proportion of micropores measuring $<10^{-4} \mathrm{~mm}^{3}$, whereas the FASF sample had a broader micropore distribution than the other two samples. Accordingly, the micropores by 

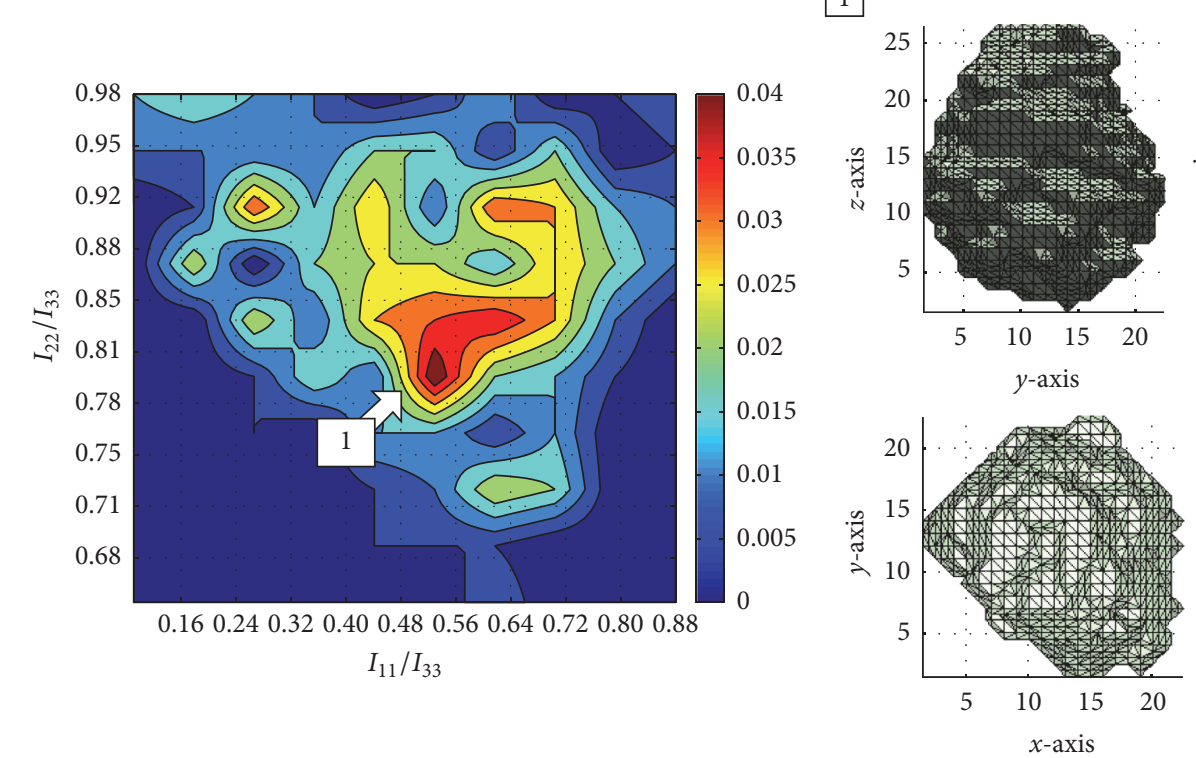

(a)

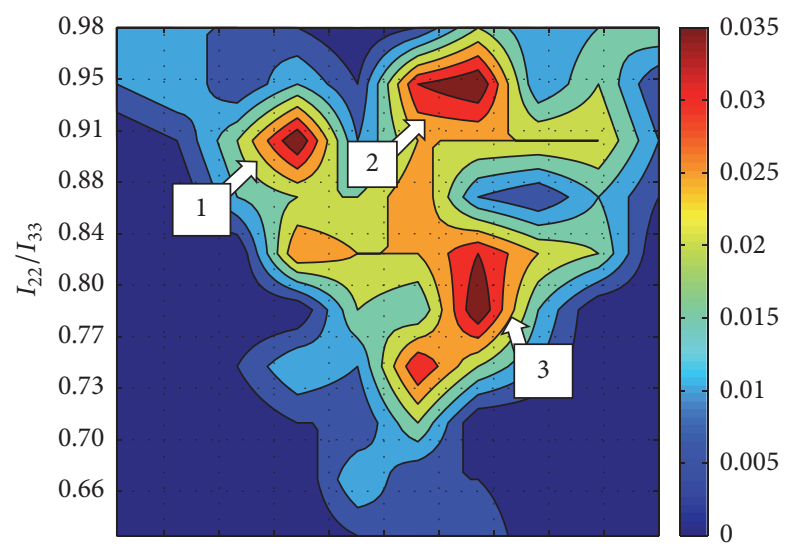

$\begin{array}{llllllllll}0.18 & 0.26 & 0.34 & 0.42 & 0.50 & 0.59 & 0.67 & 0.75 & 0.83 & 0.91\end{array}$ $I_{11} / I_{33}$

(1)
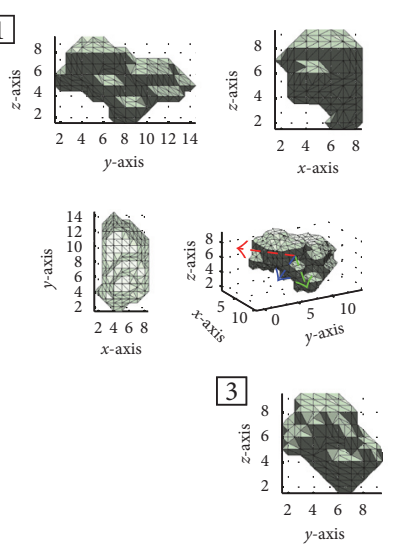
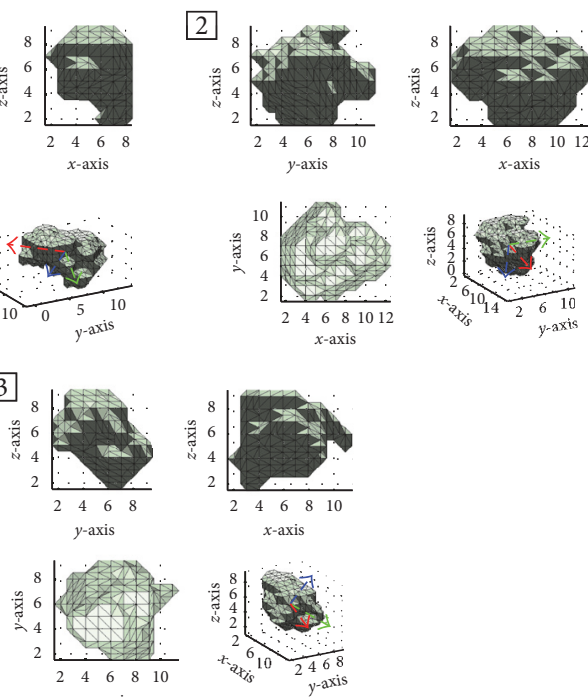

$x$-axis

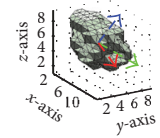

(b)

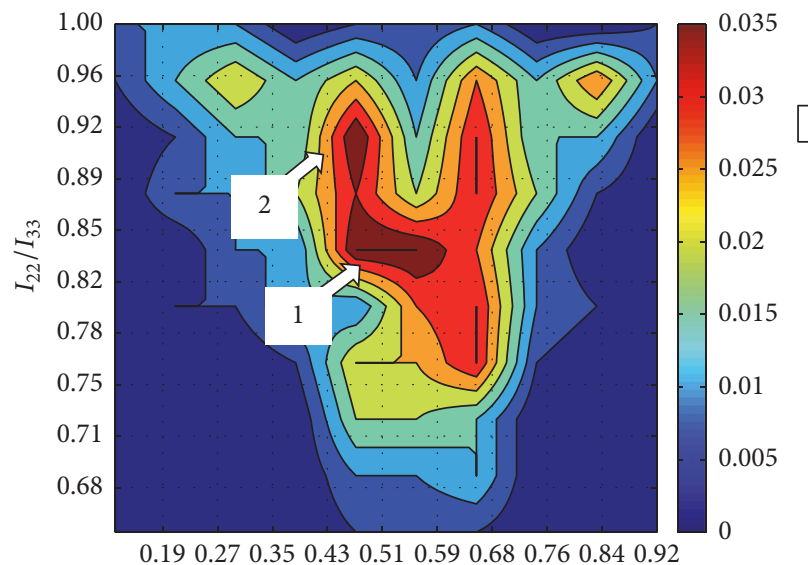

1
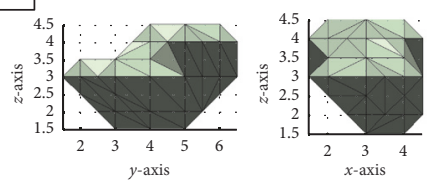

2
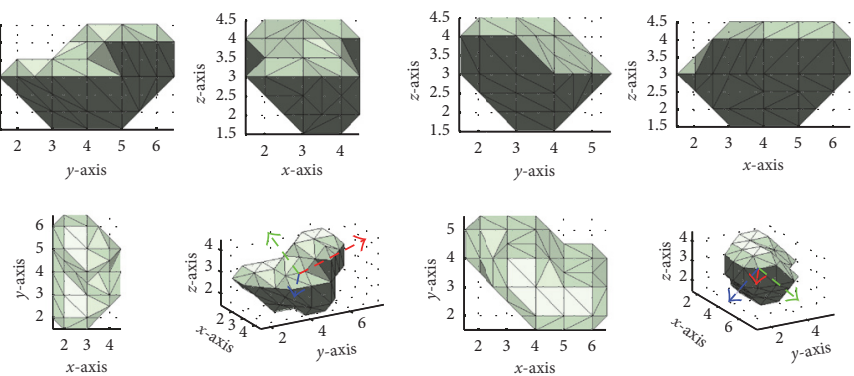

(c)

Figure 4: Continued. 

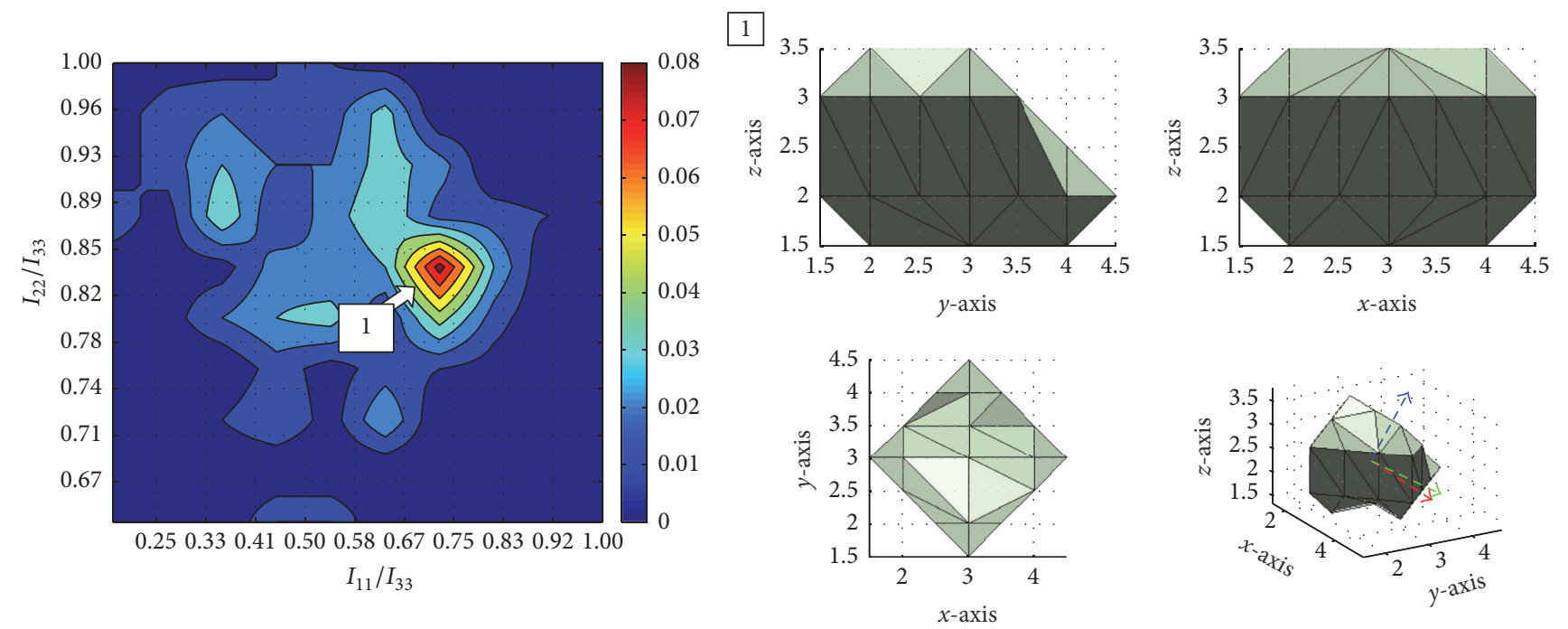

(d)

FIGURE 4: Contour maps of $I_{11} / I_{33}$ and $I_{22} / I_{33}$ ratios of the FASF sample and representative pore shapes in areas 1 3: (a) micropore volume $\geq$ $10^{-2} \mathrm{~mm}^{3}$, (b) micropore volume $10^{-3} \sim 10^{-2} \mathrm{~mm}^{3}$, (c) micropore volume $10^{-4} \sim 10^{-3} \mathrm{~mm}^{3}$, and (d) micropore volume $<10^{-4} \mathrm{~mm}^{3}$.

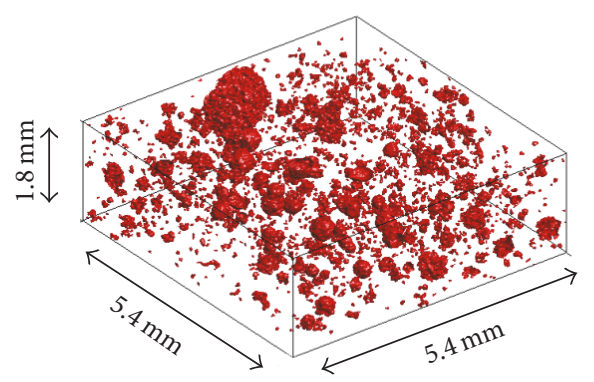

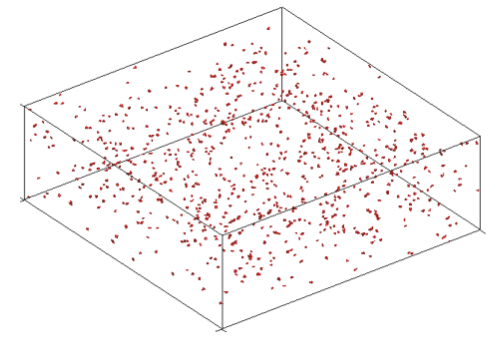

Pore volume: $<10^{-4} \mathrm{~mm}^{3}$

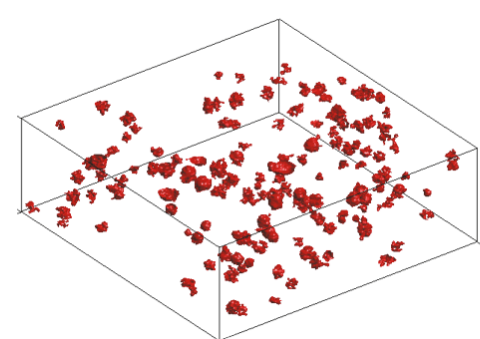

Pore volume: $10^{-3} \sim 10^{-2} \mathrm{~mm}^{3}$

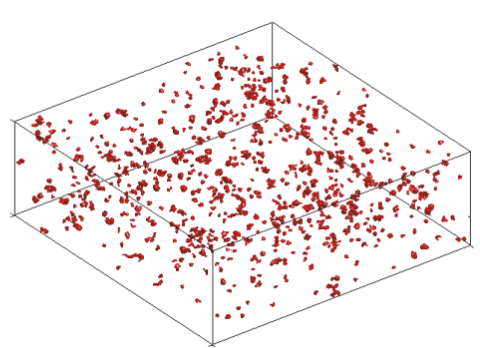

Pore volume: $10^{-4} \sim 10^{-3} \mathrm{~mm}^{3}$

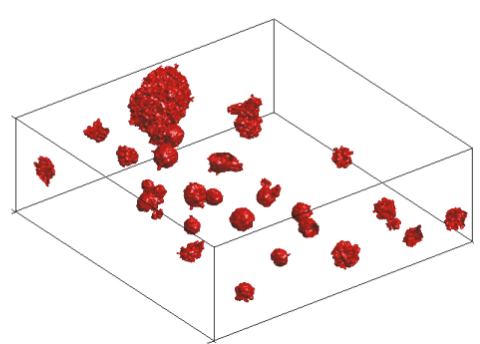

Pore volume: $\geq 10^{-2} \mathrm{~mm}^{3}$

FIGURE 5: Reconstructed 3D micropore structure of the FA sample (separated micropores based on pore-volume ranges).

cenospheres could vary, depending on different cementitious materials. This is because each binder has a different condition, which can lead to different micropore structure with cenospheres. We divided the pore-volume ranges into four groups $\left(<10^{-4} \mathrm{~mm}^{3}, 10^{-4} \sim 10^{-3} \mathrm{~mm}^{3}, 10^{-3} \sim 10^{-2} \mathrm{~mm}^{3}\right.$, and $\geq 10^{-2} \mathrm{~mm}^{3}$ of individual pore volumes) and analyzed them separately.

4.2. Micropores in FASF Sample. Figure 3 shows the 3D reconstruction of the micropore structures obtained from micro-CT data. In Figure 3, the image on the far left shows the entire structure of the micropores, while the four images to the right show the separated micropores based on the pore-volume ranges. One interesting observation is that there were no $<10^{-2} \mathrm{~mm}^{3}$ micropores near other pores that were larger than $10^{-2} \mathrm{~mm}^{3}$ (circled area in Figure 3). This might be because the large pores merged with smaller pores. Despite the visual investigation, the large number of variations in pore shapes made it difficult to define the characteristics of the shapes. Therefore, we calculated the moments of inertia of individual pores and then the eigenvalues of the moments. These eigenvalues were the principle moments $\left(I_{11}<I_{22}<\right.$ $I_{33}$ ), and we obtained the contour maps on the left side of Figure 4 using the ratios of $I_{11} / I_{33}$ and $I_{22} / I_{33}$ (moment ratios). 


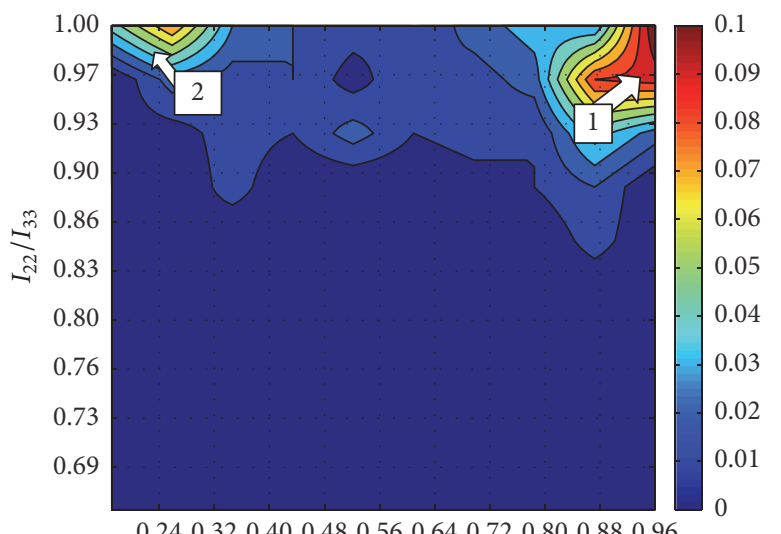

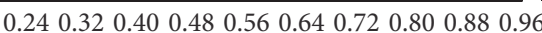
$I_{11} / I_{33}$

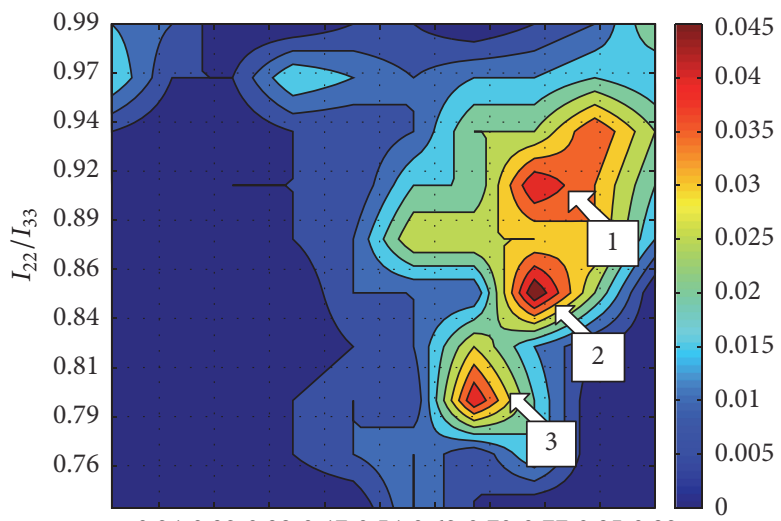

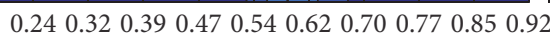
$I_{11} / I_{33}$
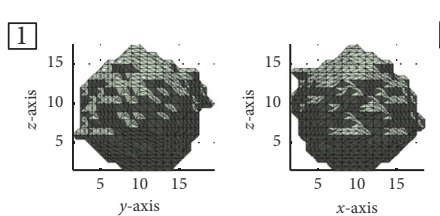

2
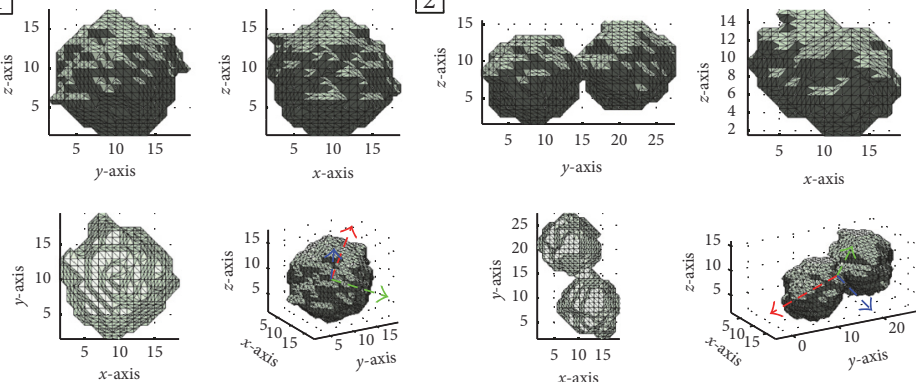

(a)
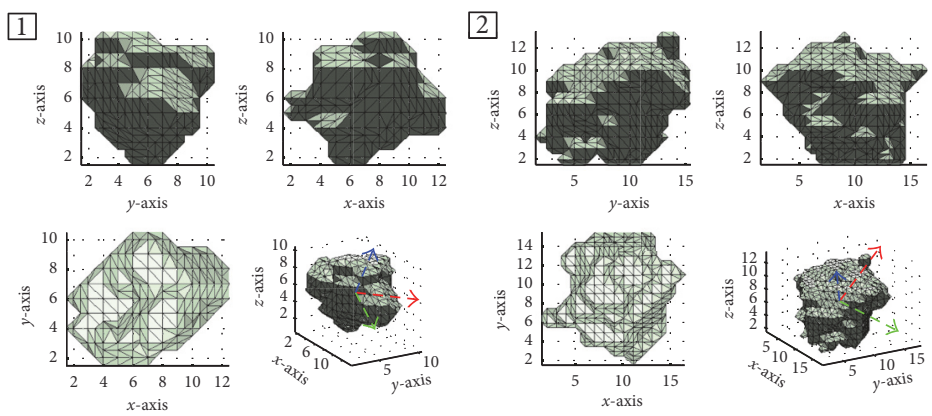

3
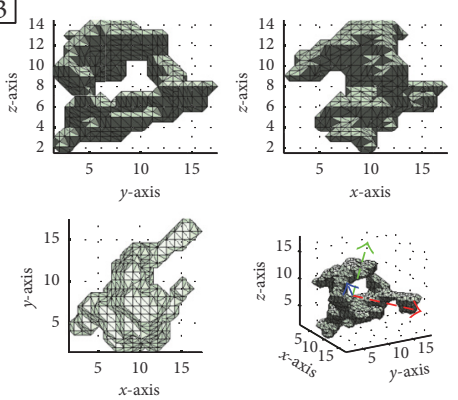

(b)

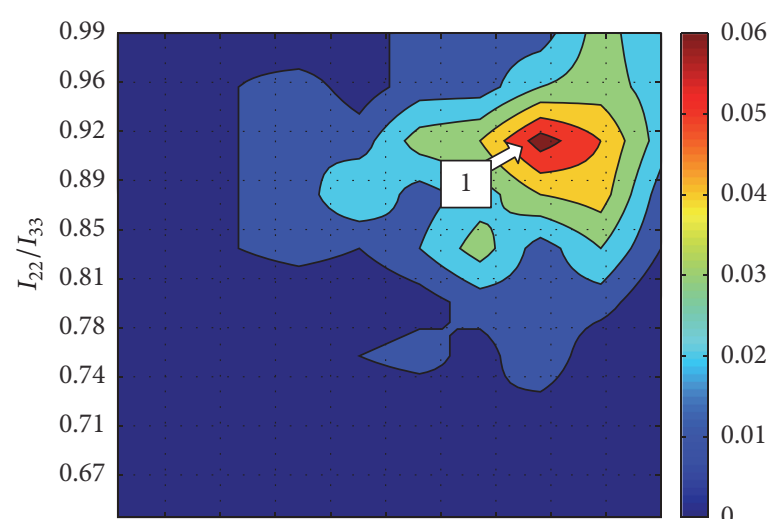

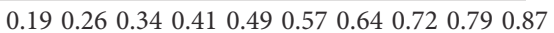
$I_{11} / I_{33}$
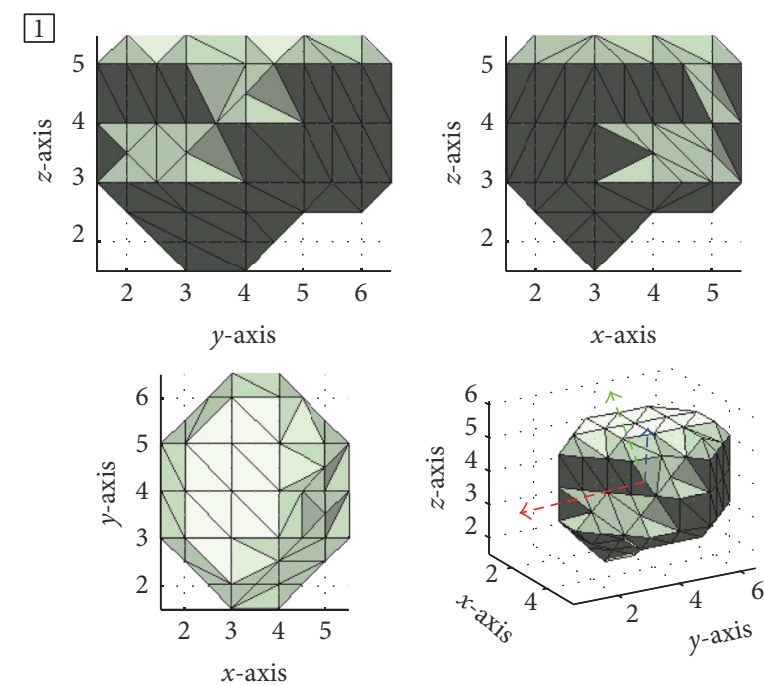

(c) 

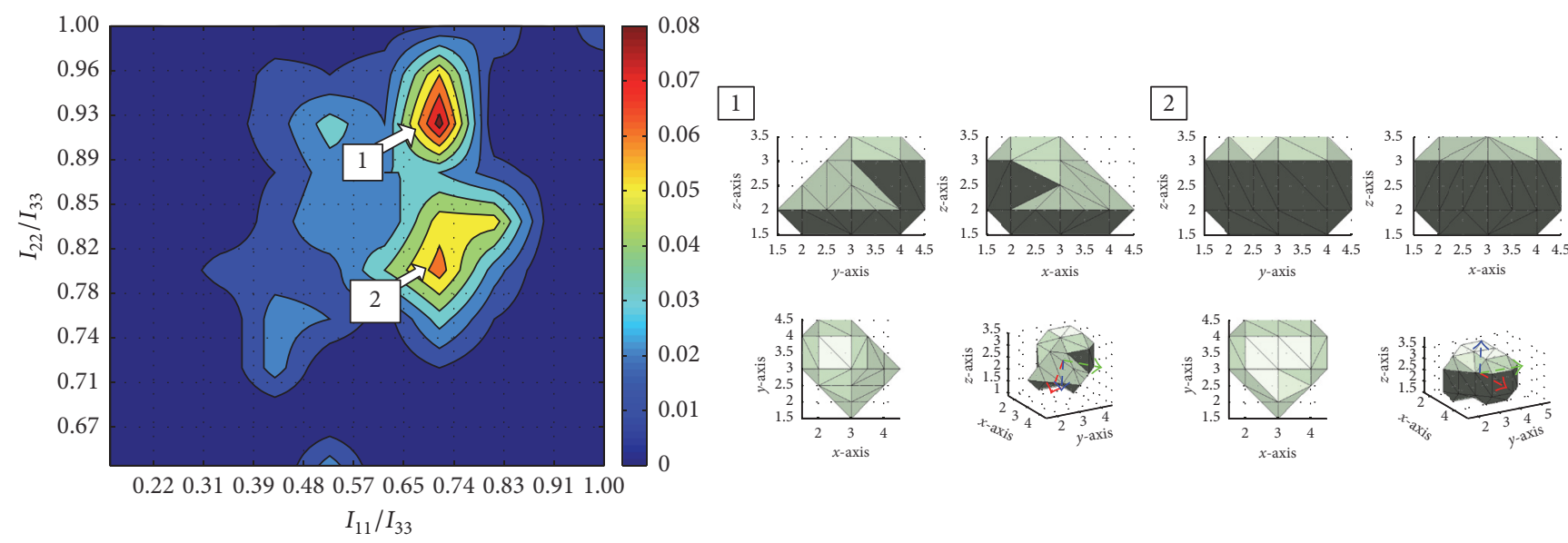

(d)

FIGURE 6: Contour maps of $I_{11} / I_{33}$ and $I_{22} / I_{33}$ ratios of the FA sample and representative pore shapes in areas 1 3: (a) micropore volume $\geq$ $10^{-2} \mathrm{~mm}^{3}$, (b) micropore volume $10^{-3} \sim 10^{-2} \mathrm{~mm}^{3}$, (c) micropore volume $10^{-4} \sim 10^{-3} \mathrm{~mm}^{3}$, and (d) micropore volume $<10^{-4} \mathrm{~mm}^{3}$.

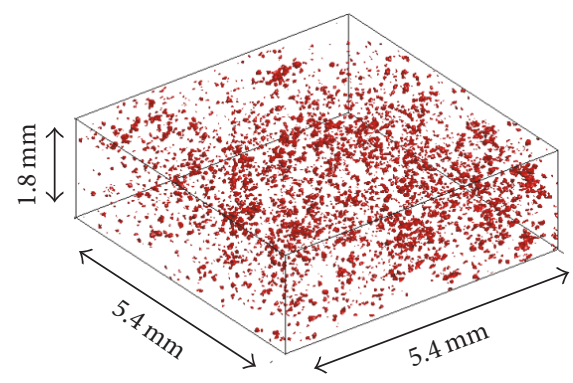

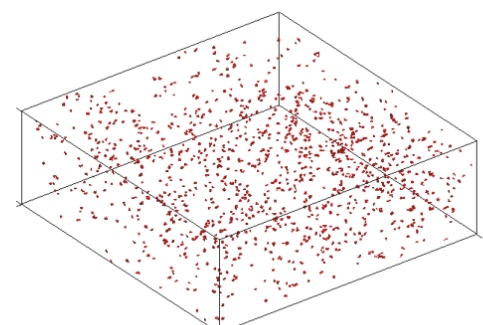

Pore volume: $<10^{-4} \mathrm{~mm}^{3}$

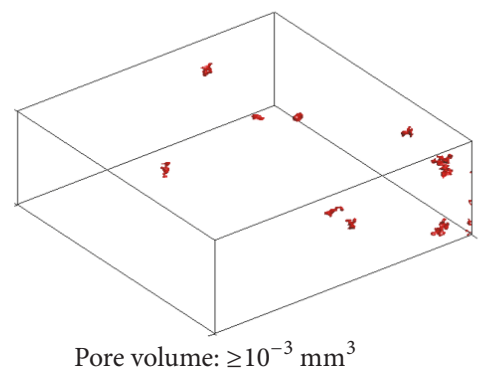

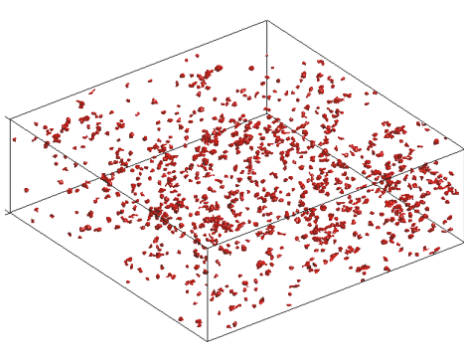

Pore volume: $10^{-4} \sim 10^{-3} \mathrm{~mm}^{3}$

FIGURE 7: Reconstructed 3D micropore structure of the PC sample (separated micropores based on pore-volume range).

The 3D features on the right side of Figure 4 also shows the representative shape of the micropores appearing at a high frequency in the moment ratios. The representative shape of the micropores with volume ranges of $<10^{-4} \mathrm{~mm}^{3}$, $10^{-4} \sim 10^{-3} \mathrm{~mm}^{3}$, and $\geq 10^{-2} \mathrm{~mm}^{3}$ was an elliptical sphere rather than a round sphere, as seen in Figures 4(a), 4(c), and $4(\mathrm{~d})$. The micropores of the $10^{-3} \sim 10^{-2} \mathrm{~mm}^{3}$ range in Figure 4(b) had more irregular shapes than those of the other ranges, shown in Figures 4(a), 4(c), and 4(d).

4.3. Micropores in FA Sample. Figure 5 shows the 3Dreconstructed micropore structure of the FA sample and four groups of pore-volume ranges. In contrast to the FASF sample, the FA sample had many pores measuring $<10^{-3} \mathrm{~mm}^{3}$ near large pores. Figure 6 shows the contour maps of the moment ratios and the representative pore shapes on the marked areas. In Figure 6(a), the micropores with volumes measuring $\geq 10^{-2} \mathrm{~mm}^{3}$ have two areas of moment ratios. The $I_{11} / I_{33}$ and $I_{22} / I_{33}$ ratios of area 1 marked in Figure 6(a) are close to 1.00 , meaning that the representative shape of the micropores in that area is a round sphere. However, the $I_{11} / I_{33}$ ratios of area 2 marked in Figure 6(a) range between 0.16 and 0.32 , and $I_{22} / I_{33}$ is close to 1.00 . With these moment ratios, the representative shape of the micropores is two connected spheres. The micropores in the volume range of $10^{-3} \sim 10^{-2} \mathrm{~mm}^{3}$ have three main areas in the contour map of Figure 6(b). Areas 1 and 2 have similar $I_{11} / I_{33}$ ratios and pore shapes. However, the pore shape in area 3 is more irregular than those in areas 1 and 2. Figures 6(c) and 6(d) show the moment ratios of the micropores with volume ranges 


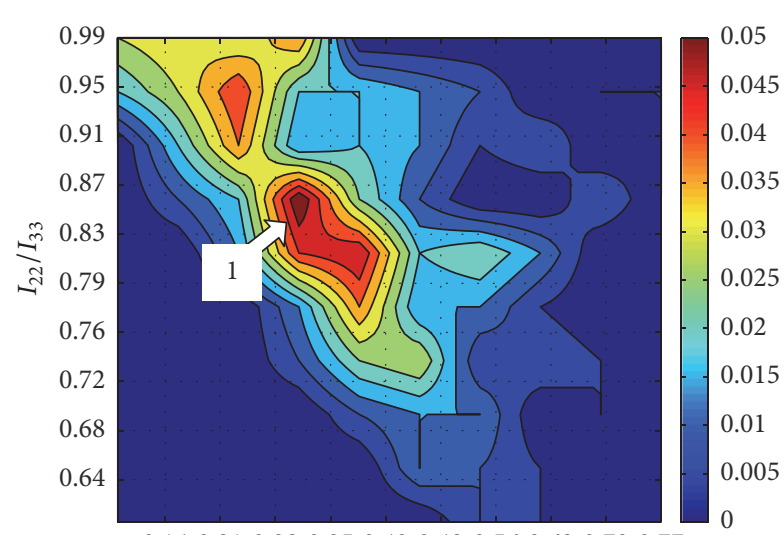

$\begin{array}{lllllllllll}0.14 & 0.21 & 0.28 & 0.35 & 0.42 & 0.49 & 0.56 & 0.63 & 0.70 & 0.77\end{array}$

$$
I_{11} / I_{33}
$$

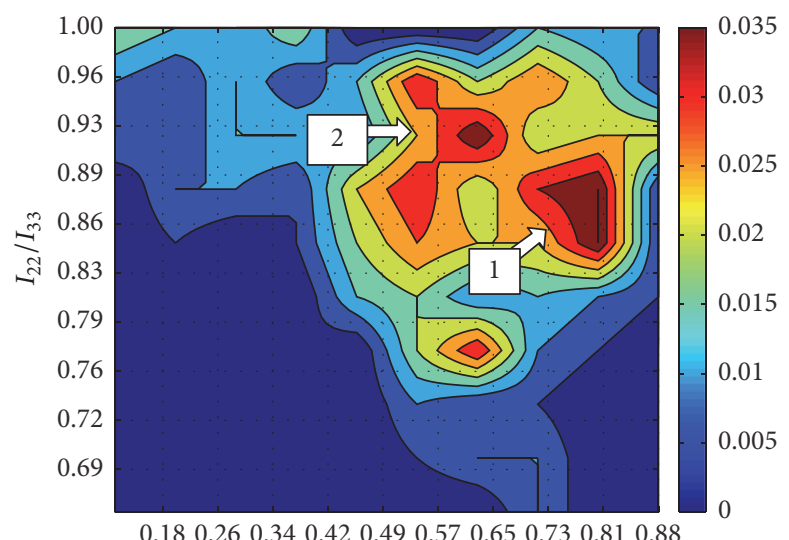

$I_{11} / I_{33}$
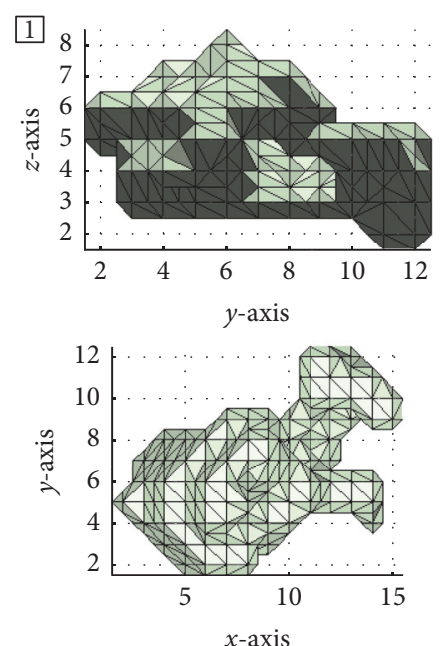

(a)
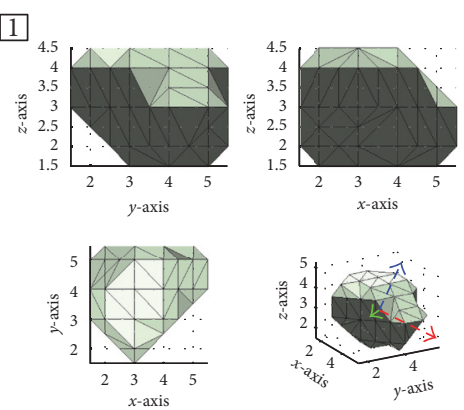

(b)
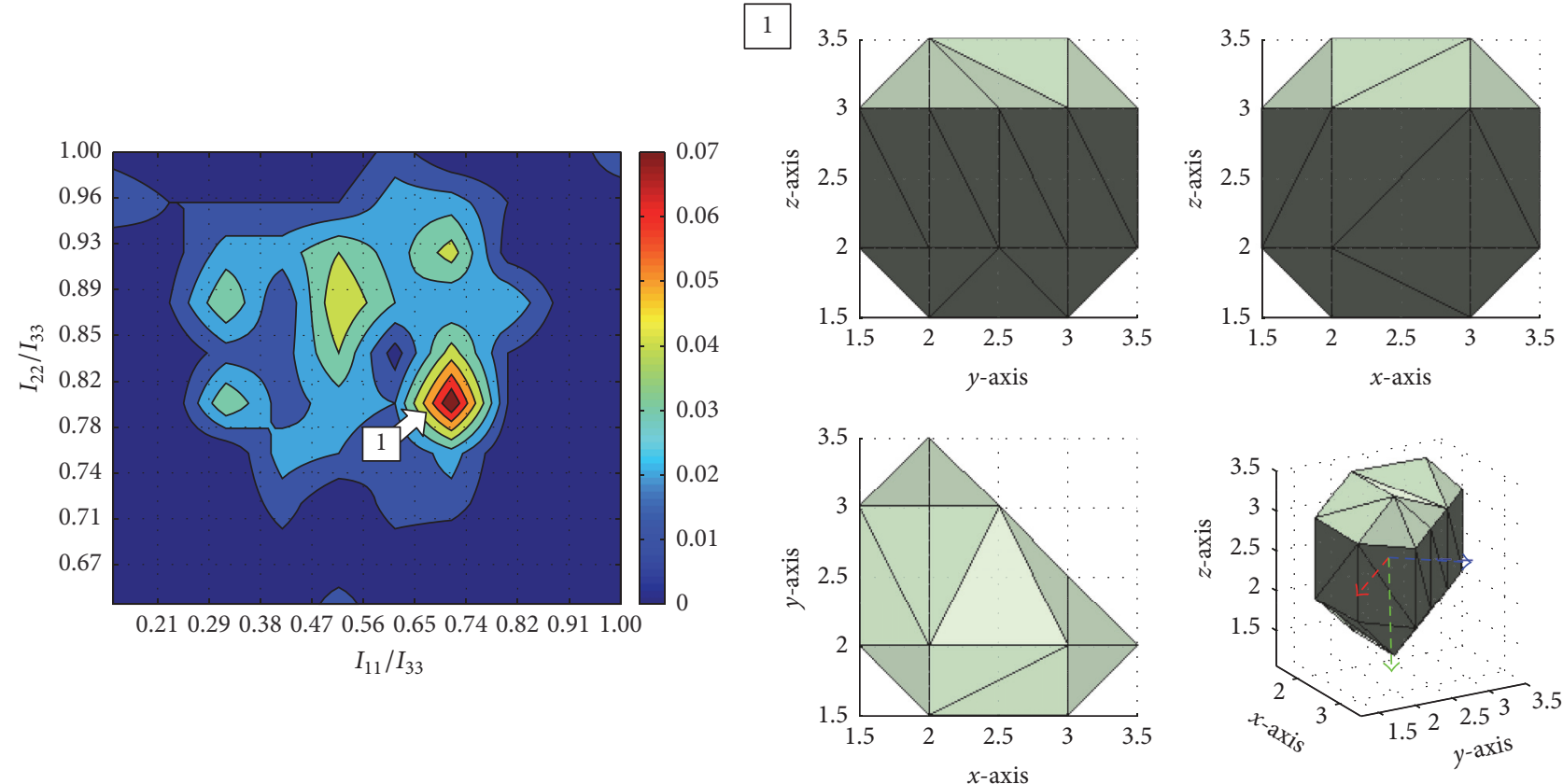

(c)
2
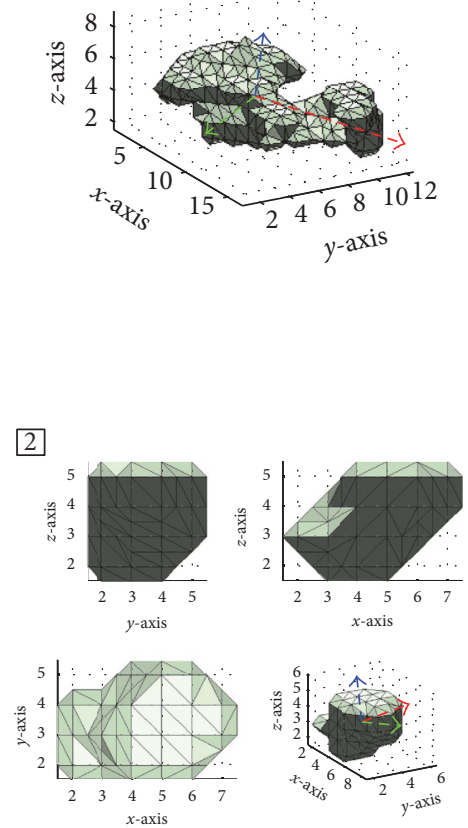


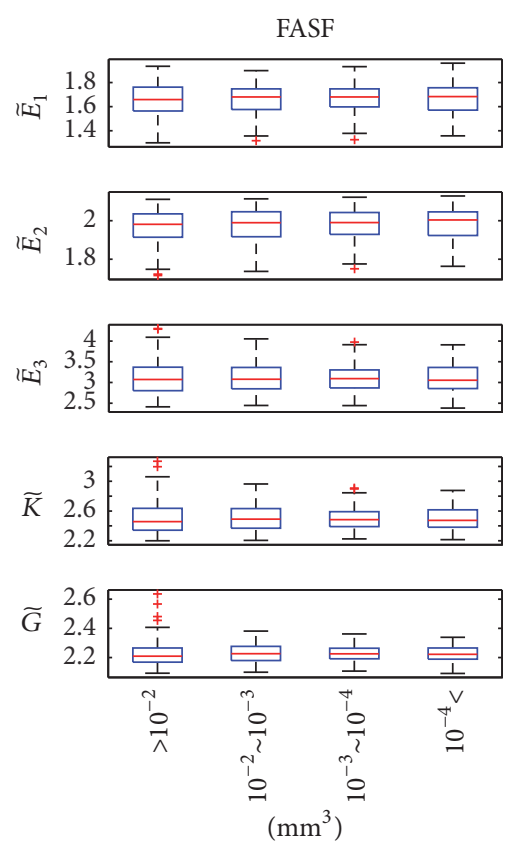

(a)
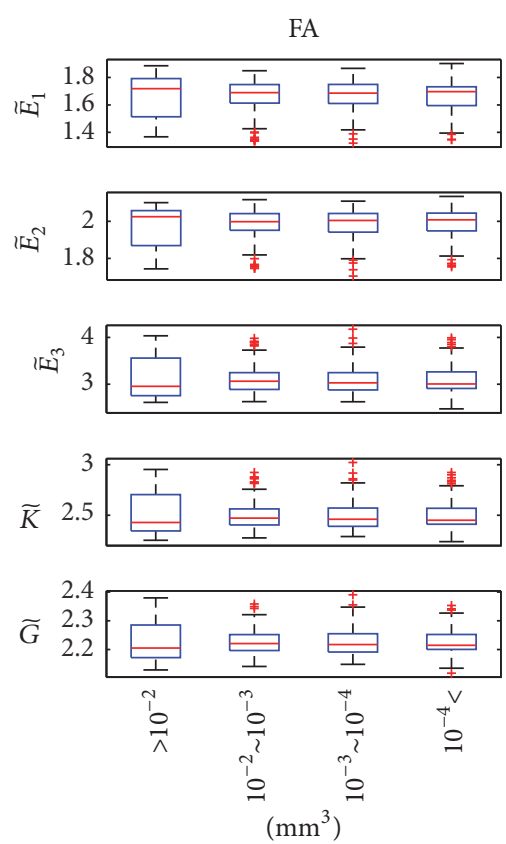

(b)
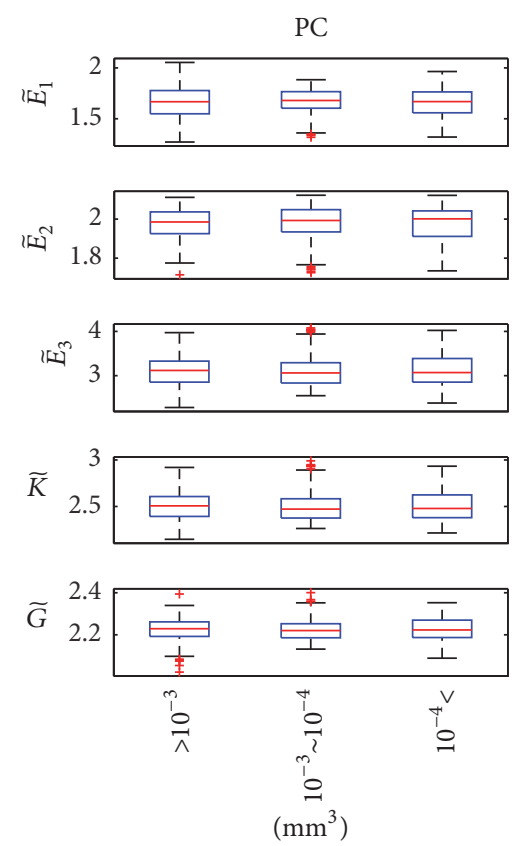

(c)

Figure 9: Dimensionless parameters $\left(\widetilde{E}_{1}, \widetilde{E}_{2}, \widetilde{E}_{3}, \widetilde{K}, \widetilde{G}\right)$ of the elastic moduli predicted by the 4-factor PCC model: (a) four pore-volume ranges in the FASF sample, (b) four pore-volume ranges in the FA sample, and (c) three pore-volume ranges in the PC sample.

of $10^{-4} \sim 10^{-3} \mathrm{~mm}^{3}$ and $<10^{-4} \mathrm{~mm}^{3}$. The pore shapes in these ranges are elliptical spheres, which are close to the shapes in the FASF sample in identical pore-volume ranges.

4.4. Micropores in PC Sample. Figure 7 shows the micropores in the PC sample. Large pores with volumes measuring $\geq 10^{-3} \mathrm{~mm}^{3}$ were not frequently observed in the PC sample. Furthermore, the pore size distribution of the PC sample was more uniform than that of the FASF and FA samples. The large pores $\left(\geq 10^{-3} \mathrm{~mm}^{3}\right)$ in area 1 of Figure $8(\mathrm{a})$ have irregular shapes, and the $I_{11} / I_{33}$ ratios mostly range from 0.14 to 0.42 . These low $I_{11} / I_{33}$ ratios originate from the elongated pore shapes in the PC sample. It is noteworthy that these low $I_{11} / I_{33}$ ratios were also observed for two connected spheres in the FA sample. Furthermore, in Figure 8(b), the representative pore shape in area 2 is more irregular than in area 1 , with a lower $I_{11} / I_{33}$ ratio in area 2 .

4.5. Predicted Influences of Micropores on Elastic Moduli. The material properties influenced by pore structures are elastic moduli of hardened materials, such as Young's modulus, bulk modulus, and shear modulus. The application of the 4-factor PCC model to micropores formed by cenosphere can show the relation between their $I_{11} / I_{33}$ and $I_{22} / I_{33}$ ratios and elastic moduli. Figure 9 shows the dimensionless parameters $\left(\widetilde{E}_{1}, \widetilde{E}_{2}, \widetilde{E}_{3}, \widetilde{K}, \widetilde{G}\right)$ of the predicted elastic moduli, which represent changes in elastic moduli induced by pore shape. In the FASF and PC samples, all five dimensionless parameters had similar values regardless of the pore-volume ranges, as the mean values and the gaps between the first and third quantiles were similar. This is because the mean values of the $I_{11} / I_{33}$ and $I_{22} / I_{33}$ ratios obtained from the micropores in the FASF and PC samples were similar. In the FA sample, the mean values of the dimensionless parameters were close together regardless of the pore-volume ranges, but the variations in the five parameters of the micropores measuring $\geq 10^{-2} \mathrm{~mm}^{3}$ were higher than those of the other volume ranges. This indicates that the connection of two pores can introduce a high variation in elastic moduli. A comparison between the FASF and FA samples showed similar influences of micropores on the elastic moduli. Furthermore, the micropores measuring $\geq 10^{-3} \mathrm{~mm}^{3}$ in the PC sample could introduce a greater variation in $\widetilde{E}_{1}$ than the FASF and FA samples due to the elongated pore shapes having low $I_{11} / I_{33}$ ratios.

\section{Conclusions}

The main purpose of the present study was to understand the structure of micropores in different cementitious pastes and their influence on the elastic moduli. We obtained the $3 \mathrm{D}$ morphologies of micropores from Portland cement paste, $\mathrm{Ca}(\mathrm{OH})_{2}-\mathrm{Na}_{2} \mathrm{CO}_{3}$-activated fly ash-silica fume, and $\mathrm{Ca}(\mathrm{OH})_{2}-\mathrm{Na}_{2} \mathrm{CO}_{3}$-activated fly ash with cenospheres of all samples at $60 \%$ of binders by weight. The following results were observed:

(i) The PC sample (cenosphere-containing Portland cement paste) had a less-broad size distribution of micropores compared to the FASF and FA samples $\left(\mathrm{Ca}(\mathrm{OH})_{2}-\mathrm{Na}_{2} \mathrm{CO}_{3}\right.$-activated fly ash-silica fume and $\mathrm{Ca}(\mathrm{OH})_{2}-\mathrm{Na}_{2} \mathrm{CO}_{3}$-activated fly ash with cenospheres). 
(ii) The FASF sample $\left(\mathrm{Ca}(\mathrm{OH})_{2}-\mathrm{Na}_{2} \mathrm{CO}_{3}\right.$-activated, cenosphere-containing fly ash-silica fume) had more irregular micropore shapes in the $10^{-3} \sim 10^{-2} \mathrm{~mm}^{3}$ pore-volume range compared to the other ranges $\left(<10^{-4} \mathrm{~mm}^{3}, 10^{-4} \sim 10^{-3} \mathrm{~mm}^{3}\right.$, and $\left.\geq 10^{-2} \mathrm{~mm}^{3}\right)$.

(iii) Two connected spherical micropores were frequently observed in the $\geq 10^{-2} \mathrm{~mm}^{3}$ range of the FA sample $\left(\mathrm{Ca}(\mathrm{OH})_{2}-\mathrm{Na}_{2} \mathrm{CO}_{3}\right.$-activated, cenosphere-containing fly ash), and the 4-factor PCC model predicted that the connected micropores would increase the variations in elastic moduli. However, the averaged values of effective elastic moduli are similar.

(iv) The PC sample had more elongated micropores than the FA and FASF samples. Furthermore, the 4-factor PCC model predicted a greater variation in Young's modulus of the PC sample compared to that of the FA and FASF samples.

\section{Conflicts of Interest}

The authors declare that there are no conflicts of interest regarding the publication of this paper.

\section{Acknowledgments}

This work was supported by Kyonggi University Research Grant 2016 (2016-001).

\section{References}

[1] A. Bilodeau, V. Sivasundaram, K. Painter, and V. Malhotra, "Durability of concrete incorporating high volumes of fly ash from sources in the U.S.A," ACI Materials Journal, vol. 91, no. 1, pp. 3-12, 1994.

[2] B. Sukumar, K. Nagamani, and R. Srinivasa Raghavan, "Evaluation of strength at early ages of self-compacting concrete with high volume fly ash," Construction and Building Materials, vol. 22, no. 7, pp. 1394-1401, 2008.

[3] S. Yoon, P. J. M. Monteiro, D. E. Macphee, F. P. Glasser, and M. S.-E. Imbabi, "Statistical evaluation of the mechanical properties of high-volume class F fly ash concretes," Construction and Building Materials, vol. 54, pp. 432-442, 2014.

[4] M. J. Dudas and C. J. Warren, "Submicroscopic model of fly ash particles," Geoderma, vol. 40, no. 1-2, pp. 101-114, 1987.

[5] R. T. Chancey, P. Stutzman, M. C. G. Juenger, and D. W. Fowler, "Comprehensive phase characterization of crystalline and amorphous phases of a Class F fly ash," Cement and Concrete Research, vol. 40, no. 1, pp. 146-156, 2010.

[6] F. Blanco, P. García, P. Mateos, and J. Ayala, "Characteristics and properties of lightweight concrete manufactured with cenospheres," Cement and Concrete Research, vol. 30, no. 11, pp. 1715-1722, 2000.

[7] S. P. McBride, A. Shukla, and A. Bose, "Processing and characterization of a lightweight concrete using cenospheres," Journal of Materials Science, vol. 37, no. 19, pp. 4217-4225, 2002.

[8] J.-Y. Wang, M.-H. Zhang, W. Li, K.-S. Chia, and R. J. Y. Liew, "Stability of cenospheres in lightweight cement composites in terms of alkali-silica reaction," Cement and Concrete Research, vol. 42, no. 5, pp. 721-727, 2012.
[9] Y. Wu, J.-Y. Wang, P. J. M. Monteiro, and M.-H. Zhang, "Development of ultra-lightweight cement composites with low thermal conductivity and high specific strength for energy efficient buildings," Construction and Building Materials, vol. 87, pp. 100-112, 2015.

[10] X. Huang, R. Ranade, Q. Zhang, W. Ni, and V. C. Li, "Mechanical and thermal properties of green lightweight engineered cementitious composites," Construction and Building Materials, vol. 48, pp. 954-960, 2013.

[11] V. Parameswaran and A. Shukla, "Processing and characterization of a model functionally gradient material," Journal of Materials Science, vol. 35, no. 1, pp. 21-29, 2000.

[12] E. Gallucci, K. Scrivener, A. Groso, M. Stampanoni, and G. Margaritondo, "3D experimental investigation of the microstructure of cement pastes using synchrotron X-ray microtomography $(\mu \mathrm{CT})$," Cement and Concrete Research, vol. 37, no. 3, pp. 360-368, 2007.

[13] J. L. Provis, R. J. Myers, C. E. White, V. Rose, and J. S. J. Van Deventer, "X-ray microtomography shows pore structure and tortuosity in alkali-activated binders," Cement and Concrete Research, vol. 42, no. 6, pp. 855-864, 2012.

[14] S. R. Chae, J. Moon, S. Yoon et al., "Advanced nanoscale characterization of cement based materials using X-ray synchrotron radiation: a review," International Journal of Concrete Structures and Materials, vol. 7, no. 2, pp. 95-110, 2013.

[15] J. Moon, P. D. Kalb, L. Milian, and P. A. Northrup, "Characterization of a sustainable sulfur polymer concrete using activated fillers," Cement and Concrete Composites, vol. 67, pp. 20-29, 2016.

[16] B. Drach, A. Drach, and I. Tsukrov, "Characterization and statistical modeling of irregular porosity in carbon/carbon composites based on X-ray microtomography data," ZAMM Zeitschrift fur Angewandte Mathematik und Mechanik, vol. 93, no. 5, pp. 346-366, 2013.

[17] D. Jeon, Y. Jun, Y. Jeong, and J. E. Oh, "Microstructural and strength improvements through the use of $\mathrm{Na}_{2} \mathrm{CO}_{3}$ in a cementless $\mathrm{Ca}(\mathrm{OH})_{2}$-activated class F fly ash system," Cement and Concrete Research, vol. 67, pp. 215-225, 2015.

[18] B. Drach, I. Tsukrov, T. Gross et al., "Numerical modeling of carbon/carbon composites with nanotextured matrix and 3D pores of irregular shapes," International Journal of Solids and Structures, vol. 48, no. 18, pp. 2447-2457, 2011. 

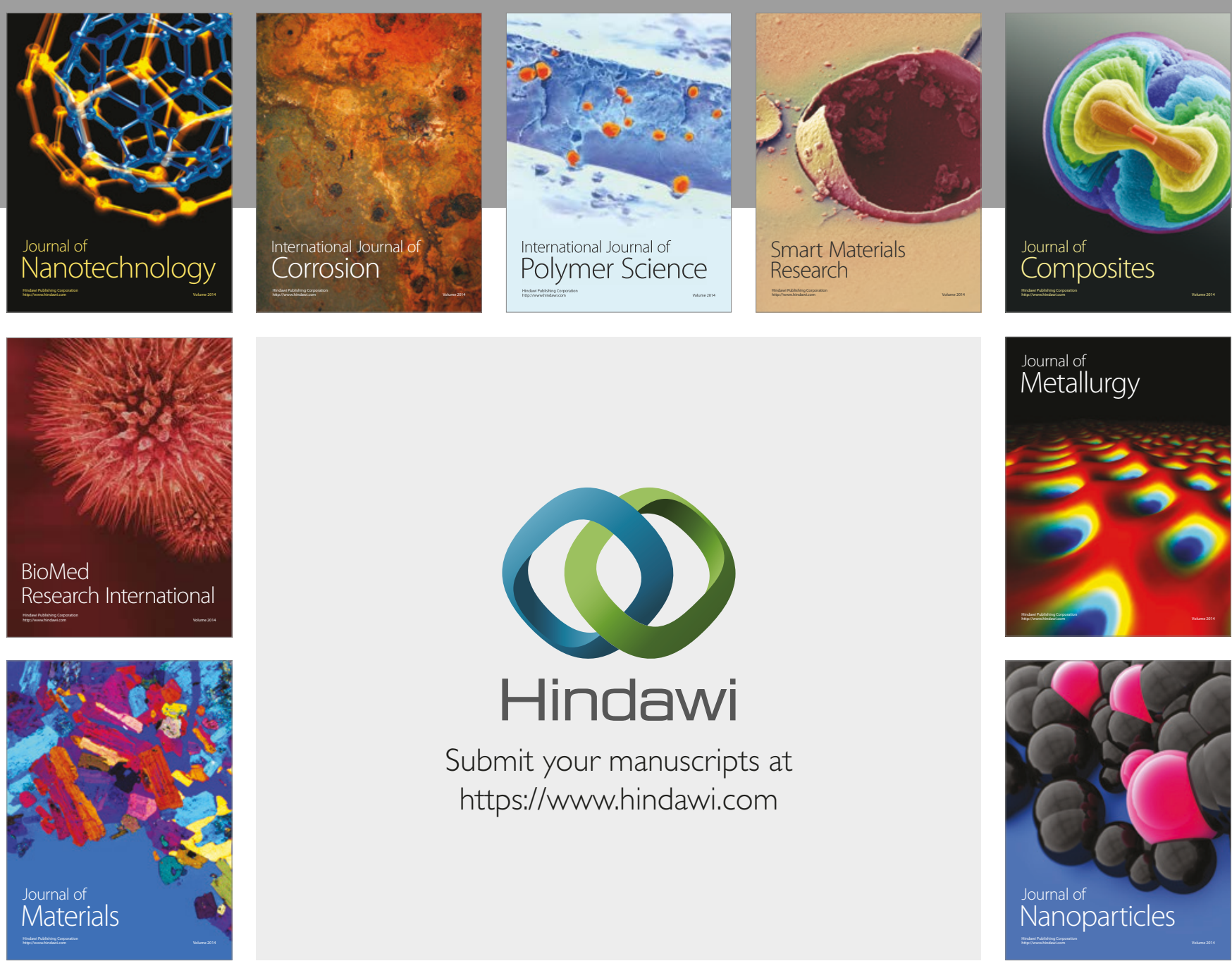

\section{Hindawi}

Submit your manuscripts at

https://www.hindawi.com
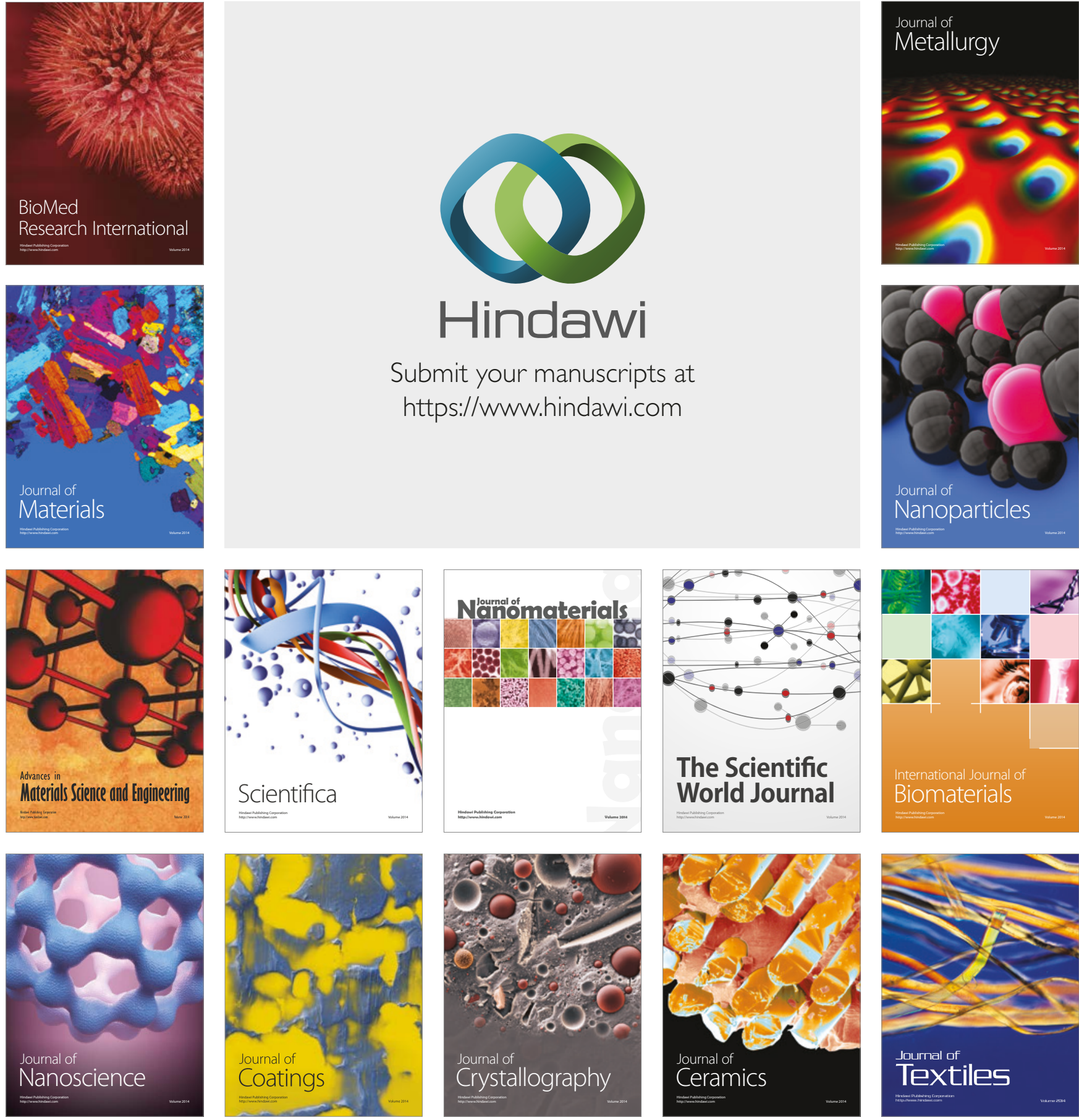

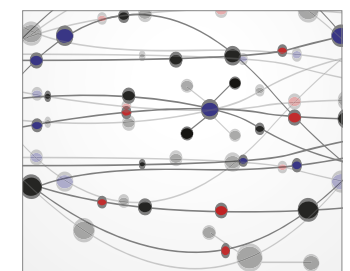

The Scientific World Journal
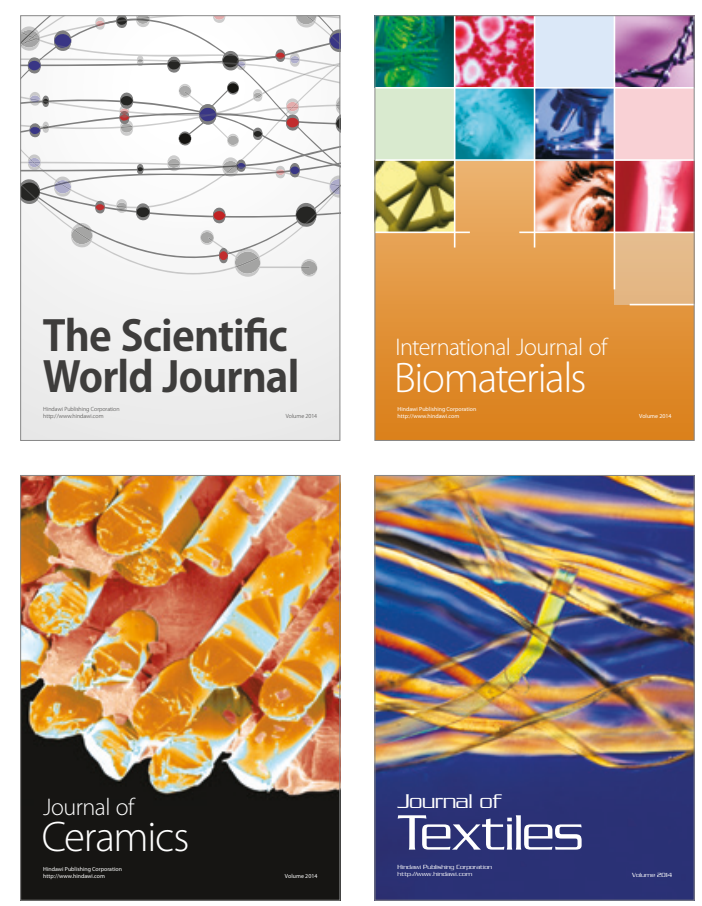